\title{
An assessment of undergraduate paramedic students' empathy levels
}

\author{
Brett Williams', Malcolm Boyle', Richard Brightwell2 ${ }^{2}$, Scott Devenish ${ }^{3}$, Peter Hartley4, Michael McCall5, \\ Paula McMullen', Graham Munro', Peter 0'Meara ${ }^{7}$, Vanessa Webb ${ }^{1}$
}

${ }^{1}$ Department of Community Emergency Health and Paramedic Practice, Monash University, Australia

${ }^{2}$ Paramedical Science, Faculty of Computing, Health and Science, Edith Cowan University, Australia

${ }^{3}$ School of Public Health, Queensland University of Technology, Australia

${ }^{4}$ Faculty of Health, Engineering and Science, Victoria University, Australia

${ }^{5}$ School of Medicine, University of Tasmania, Australia

${ }^{6}$ School of Biomedical Sciences, Charles Sturt University, Australia

${ }^{7}$ Faculty of Health Sciences, La Trobe Rural Health School, Australia

Correspondence: Brett Williams, Department of Community Emergency Health and Paramedic Practice, Monash University - Peninsula Campus, PO Box 527, McMahons Road, Frankston, Victoria, Australia, 3199.

Email:brett.williams@monash.edu

Accepted: May 21, 2012

\begin{abstract}
Objectives: The purpose of this study was to assess the extent of empathy in paramedic students across seven Australian universities.

Methods: A cross-sectional study using a paper-based questionnaire employing a convenience sample of first, second, and third year undergraduate paramedic students. Student empathy levels were measured using the Medical Condition Regard Scale (MCRS).

Results: A total of 783 students participated in the study of which $57 \%$ were females. The medical conditions: intellectual disability, attempted suicide, and acute mental illness all produced mean scores above 50 suggesting good

12.29). There was a statistically significant difference between males $(M=49.79)$ and females $(M=51.61)$ for patients with intellectual disability $\left(\mathrm{t}_{(778)}=2.76, \mathrm{p}=0.006\right)$.

Conclusions: The findings from this study found that student reported poor empathetic regard for patients with substance abuse, while female students report higher levels of empathy than their male colleagues across each medical condition. The overall findings provide a framework for educators to begin constructing guidelines focusing on the need to incorporate, promote and instil empathy into paramedic students in order to better prepare them for future out-of-hospital healthcare practice.
\end{abstract} empathetic regard, while patients presenting with substance abuse produced the lowest mean score $(\mathrm{M}=41.57, \mathrm{SD}=$

Keywords: Empathy, undergraduates, paramedics

\section{Introduction}

The importance of empathy in establishing a positive and effective healthcare provider - patient relationship has been well documented in previous literature. Many definitions of empathy exist, but in its most basic form empathy is defined as an appreciation of another person's situation without personal emotional involvement. ${ }^{1}$ Empathy, for healthcare workers, is the ability to foster an understanding of a patient's circumstances, feelings and perceptions whilst retaining one's professional objectivity in order to deliver effective patient care. ${ }^{2}$ It is the process by which the provider acknowledges the internal frame of reference of another individual, enabling them to reflect on the consequences of their actions on the welfare of others. ${ }^{3}$ Empathy has been linked to positive patient outcomes, and has been credited with optimising levels of interpersonal communication, trust and understanding between patients and their healthcare providers. ${ }^{4}$ Whilst empathy is an essential attribute of all healthcare professionals, the empathetic capacity of paramedics is of particular importance. An individual's contact with a paramedic in a perceived emergency situation may stem from an event that could essentially forever change the life of that patient, their next of kin, or relatives. This contact is of a relatively short duration, and often occurs in an acute and highly emotional envi- 
ronment. ${ }^{5}$ It is therefore imperative that the human aspect of the situation is put into perspective through an empathetic response to the patient, family and friends to reduce the risk of the medical and technical aspects of the job consuming the paramedic. ${ }^{5} \mathrm{~A}$ number of papers purport that the possession of even basic empathy is crucial in the avoidance of inadequate communication and misunderstanding which forms the foundation of substandard care. ${ }^{5,6}$

Kliszcz and colleagues describe empathy not only as a personal attitude, but also as a tangible skill. ${ }^{7}$ It is therefore reasonable to expect that the value of an empathetic response to the patient, family, and friends be taught to undergraduate paramedic students alongside more traditional clinical skills and procedures. However, the amorphous interpretations of what empathetic behaviour entails, along with the difficulties encountered in teaching and assessing such a skill, means that many educators struggle to adequately incorporate an understanding of empathy into the curriculum. Given the well-established importance of the value of empathetic behaviour in the healthcare industry, this deficit in teaching may result in a mismatch between undergraduate student education and graduate professional requirements.

There are limited studies on paramedic empathy levels $s^{3,5,6,8}$ in comparison to other healthcare professions, with only one study identified as specifically examining student paramedics. ${ }^{2}$ Conversely a number of papers exist on other healthcare students, ${ }^{9-13}$ with the empathy levels of nursing students ${ }^{14,15}$ and medical students ${ }^{16-19}$ having been particularly well researched. Commonly reported findings from these studies include the inability to practice empathetically at a senior level if not mastered at a junior level, higher empathy in patient-oriented rather than technologyoriented specialties, higher female empathy levels compared to male, and a general decline in overall empathy levels as students progress through their course.

Although paramedic training differs from university-touniversity, the importance of an effective patient-paramedic relationship establishment is a basic requirement. All seven universities included in this study provide paramedic undergraduate education to students in a pre-employment model, with similar attributes and ethics instilled in students upon graduation. The objective of this study was to assess the extent of empathy in paramedic students across seven Australian universities

\section{Method}

\section{Design}

A cross-sectional study using a paper-based questionnaire employing a convenience sample of first, second, and third year undergraduate paramedic students.

\section{Participants}

Ethics approval was initially obtained from the Monash
University Human Research Ethics Committee (MUHREC) and then from each participating university human research ethics committee. Students enrolled in undergraduate paramedic programs from Monash University (MU), Charles Sturt University (CSU), Victoria University (VU), Edith Cowan University (ECU), University of Tasmania (UT), La Trobe University (LTU), and Queensland University of Technology (QUT) provided data for the analysis. There were 1,821 students eligible for inclusion in the study. Inclusion criteria for the study were being enrolled on a full time basis in one of the paramedic courses.

\section{Instrumentation}

Student empathy levels were measured using the Medical Condition Regard Scale (MCRS) items are rated on a 6point Likert scale ( $1=$ strongly disagree, $6=$ strongly agree $)$ (score 11-66). To reduce the confounding effect of acquiescence responding, five items are worded negatively, which are later reversed scored for data analysis. The MCRS has reported validity and reliability. ${ }^{20}$

\section{Procedures}

At the conclusion of a lecture for each of the undergraduate programs, students were invited to participate in the study. Students were provided with an explanatory statement and were informed that participation was voluntary and anonymous. A non-teaching member of staff facilitated the process and participants were administered a questionnaire containing the MCRS and a brief set of demographic questions. The scale took students approximately ten minutes to complete and consent was implied by its completion and submission.

\section{Data analysis}

The SPSS program (Statistical Package for the Social Sciences Version 18.0, SPSS Inc., Chicago, Illinois, U.S.A.) was used for data storage, tabulation, and the generation of descriptive and inferential statistics. Descriptive statistics means and standard deviations (SD) were used to summarise the demographic and some of the MCRS measurement data. Inferential statistics, t-tests and one-way analysis of variance (ANOVA), including post hoc tests, were used to compare the differences between age groups, gender, year level, and university. The effect sizes (eta) were calculated to evaluate the findings results are considered statistically significant if the $\mathrm{p}$ value is $<0.05$.

\section{Results}

\section{Participant demographics}

There were 783 students who participated in the study and were enrolled in the respective undergraduate paramedic programs from MU, CSU, VU, ECU, UT, LTU and QUT. This represents a $42.9 \%$ response rate. The majority of participants were enrolled in first year $n=377$ (48.1\%), 
predominately female $\mathrm{n}=449(57.3 \%)$, were mostly under the age of $25 \mathrm{n}=568(72.6 \%)$ and participating in a single paramedic degree $n=680(86.8 \%)$. The full demographic distribution, including response rates are outlined in Table 1.

Table 1. Participants demographic $(\mathrm{N}=783)$

\begin{tabular}{llcc}
\hline Variable & Descriptor & $(\%)$ & $\begin{array}{c}\text { Response rate } \\
\mathrm{n}(\%)\end{array}$ \\
\hline University & CSU & 10 & $75(19)$ \\
& ECU & 3 & $26(13)$ \\
& $\mathrm{MU}$ & 16 & $126(46)$ \\
& QUT & 13 & $100(14)$ \\
& VU & 43 & $338(50)$ \\
& UT & 14 & $106(73)$ \\
Gender & LTU & 2 & $12(50)$ \\
Age & Male & 42 & $331(36)$ \\
& Female & 57 & $449(41)$ \\
& $17-21$ years & 47 & 370 \\
& $22-25$ years & 25 & 198 \\
& $26-30$ years & 14 & 107 \\
& $31-35$ years & 5 & 39 \\
Year level & $>36$ years & 8 & 61 \\
& Year 1 & 48 & 377 \\
& Year 2 & 31 & 246 \\
Course type & Year 3 & 19 & 150 \\
& Single degree & 87 & 680 \\
& Double degree & 13 & 102 \\
\hline
\end{tabular}

\section{Mean scores and internal consistency}

Mean scores and standard deviations (SD) for the MCRS: MCRS - intellectual disability 50.91 (SD=9.31); MCRS substance abuse, 41.57 ( $\mathrm{SD}=12.29)$; MCRS - attempted suicide, 50.24 ( $\mathrm{SD}=12.09)$; and MCRS - mental illness, 50.82 $(\mathrm{SD}=12.08)$. Students from CSU produced the highest mean scores for intellectual disability $53.64(\mathrm{SD}=11.21)$, substance abuse 44.12 ( $\mathrm{SD}=16.84)$, and acute mental illness 55.21 $(\mathrm{SD}=13.76)$. There was a low regard towards substance abuse, $41.57(\mathrm{SD}=12.29)$ while other medical conditions mean scores were above 50 . Of the universities, both MU and QUT produced the lowest scores across the four medical conditions. For the full range of results see Table 2 .

The internal consistency was measured using Cronbach's alpha coefficient. The resultant alpha coefficients for each of the scales were: MCRS - intellectual disability $\alpha=0.82$; MCRS - substance abuse $\alpha=0.89$; MCRS attempted suicide $\alpha=0.90$; MCRS - mental illness $\alpha=0.92$ which were well above the commonly used 0.70 benchmark for scale reliability. ${ }^{21}$ There was a statistically significant difference in the regard for intellectual disability between universities $\left(\mathrm{F}_{(776)}=1.05, \mathrm{p}=0.004\right)$ and age groups $\left(\mathrm{F}_{(782)}=1.46, \mathrm{p}=0.036\right)$. Post-hoc comparisons using Tukey HSD indicated that the mean score for ECU $(M=32.77$, $\mathrm{SD}=7.79)$ was significantly different from $\mathrm{MU}(\mathrm{M}=48.65$, $\mathrm{SD}=8.60)$, and $\mathrm{VU}(\mathrm{M}=51.43, \mathrm{SD}=9.59)$.

There was a statistically significant difference for the diagnostic group intellectual disability between males
$(\mathrm{M}=49.79, \mathrm{SD}=10.21)$ and females $\left[\mathrm{M}=51.61, \mathrm{SD}=8.22, \mathrm{t}_{(778)}\right.$ $=2.76, \mathrm{p}=0.006$ (two tailed) . The magnitude of the differences in the means (mean difference $=0.182,95 \% \mathrm{CI}=0.527$ to 3.12) was small (eta=0.10). Females also produced higher mean scores for the acute mental illness group $(M=51.53$, $\mathrm{SD}=10.67)$ compared with males $\left[\mathrm{M}=49.55, \mathrm{SD}=13.22, \mathrm{t}_{(778)}\right.$ $=2.30, \mathrm{p}=0.021$ (two tailed)]. The magnitude of the differences in the means (mean difference $=0.197,95 \% \mathrm{CI}=0.296$ to 3.65 ) was small (eta=0.11). There was also no statistical difference for the other medical conditions. See Table 3 for a summary of the MCRS results.

Table 2. MCRS mean and standard deviation $(\mathrm{N}=783)$

\begin{tabular}{|c|c|c|c|c|}
\hline Variable & $\begin{array}{l}\text { MCRS } \\
\text { Intellectual } \\
\text { Disability } \\
\text { (SD) }\end{array}$ & $\begin{array}{l}\text { MCRS } \\
\text { Substance } \\
\text { Abuse } \\
\text { (SD) }\end{array}$ & $\begin{array}{l}\text { MCRS } \\
\text { Attempted } \\
\text { Suicide } \\
\text { (SD) }\end{array}$ & $\begin{array}{c}\text { MCRS } \\
\text { Acute Mental } \\
\text { Illness } \\
\text { (SD) }\end{array}$ \\
\hline CSU & $\begin{array}{c}53.64 \\
(11.26)\end{array}$ & $\begin{array}{c}44.12 \\
(16.85)\end{array}$ & $\begin{array}{c}53.04 \\
(14.69)\end{array}$ & $\begin{array}{c}55.21 \\
(13.75)\end{array}$ \\
\hline ECU & $\begin{array}{l}52.77 \\
(7.79)\end{array}$ & $\begin{array}{c}42.73 \\
(11.61)\end{array}$ & $\begin{array}{l}54.85 \\
(8.42)\end{array}$ & $\begin{array}{c}51.38 \\
(10.34)\end{array}$ \\
\hline MU & $\begin{array}{l}48.65 \\
(8.61)\end{array}$ & $\begin{array}{c}41.46 \\
(10.62)\end{array}$ & $\begin{array}{c}48.25 \\
(11.24)\end{array}$ & $\begin{array}{c}49.96 \\
(11.46)\end{array}$ \\
\hline QUT & $\begin{array}{l}50.35 \\
(9.49)\end{array}$ & $\begin{array}{c}39.57 \\
(11.84)\end{array}$ & $\begin{array}{c}49.69 \\
(13.06)\end{array}$ & $\begin{array}{c}49.71 \\
(12.27)\end{array}$ \\
\hline VU & $\begin{array}{l}51.43 \\
(9.59)\end{array}$ & $\begin{array}{c}41.71 \\
(12.52)\end{array}$ & $\begin{array}{c}50.25 \\
(12.22)\end{array}$ & $\begin{array}{c}50.63 \\
(12.85)\end{array}$ \\
\hline UT & $\begin{array}{l}49.79 \\
(7.38)\end{array}$ & $\begin{array}{c}41.12 \\
(10.47)\end{array}$ & $\begin{array}{c}49.96 \\
(10.46)\end{array}$ & $\begin{array}{l}50.13 \\
(9.05)\end{array}$ \\
\hline LTU & $\begin{array}{l}53.67 \\
(5.50)\end{array}$ & $\begin{array}{l}40.83 \\
(7.03)\end{array}$ & $\begin{array}{l}50.33 \\
(6.83)\end{array}$ & $\begin{array}{l}51.92 \\
(4.64)\end{array}$ \\
\hline Male & $\begin{array}{c}49.79 \\
(10.22)\end{array}$ & $\begin{array}{c}41.21 \\
(13.13)\end{array}$ & $\begin{array}{c}49.65 \\
(12.94)\end{array}$ & $\begin{array}{c}49.55 \\
(13.22)\end{array}$ \\
\hline Female & $\begin{array}{l}51.61 \\
(8.22)\end{array}$ & $\begin{array}{c}41.77 \\
(11.31)\end{array}$ & $\begin{array}{c}50.47 \\
(11.01)\end{array}$ & $\begin{array}{c}51.53 \\
(10.67)\end{array}$ \\
\hline Year 1 & $\begin{array}{l}50.67 \\
(9.13)\end{array}$ & $\begin{array}{c}41.75 \\
(11.45)\end{array}$ & $\begin{array}{c}50.64 \\
(11.53)\end{array}$ & $\begin{array}{c}50.81 \\
(11.08)\end{array}$ \\
\hline Year 2 & $\begin{array}{c}51.08 \\
(10.15)\end{array}$ & $\begin{array}{c}41.32 \\
(13.37)\end{array}$ & $\begin{array}{c}49.92 \\
(12.93)\end{array}$ & $\begin{array}{c}51.08 \\
(12.96)\end{array}$ \\
\hline Year 3 & $\begin{array}{l}51.08 \\
(8.55)\end{array}$ & $\begin{array}{c}41.21 \\
(11.94)\end{array}$ & $\begin{array}{c}49.49 \\
(11.72)\end{array}$ & $\begin{array}{c}50.21 \\
(12.74)\end{array}$ \\
\hline Year 4 & $\begin{array}{l}53.50 \\
(5.06)\end{array}$ & $\begin{array}{c}46.30 \\
(20.01)\end{array}$ & $\begin{array}{c}54.20 \\
(17.25)\end{array}$ & $\begin{array}{c}54.30 \\
(16.68)\end{array}$ \\
\hline
\end{tabular}

\section{Discussion}

This study is believed to be the first in Australia to look at paramedic student empathy levels at a national level across multiple universities that have paramedic programs. Although a number of empathy studies have been undertaken on a variety of undergraduate healthcare students, there are few paramedic empathy research papers which can be used to provide context to this study.

Our findings found females produced higher mean scores than males on each medical condition and support the multitude of empathy studies on healthcare students, where females were identified as being more empathetic than their male counterparts. ${ }^{7,910,16,18}$ There is debate amongst academics as to how to explain this often cited phenomenon. Such hypotheses include structural and neural circulatory differences in the brain, ${ }^{22}$ as well as suggestions that men are predisposed to being relatively unemotional in order to facilitate enhanced rational deci- 
sion making. ${ }^{23}$ Additional anthropologically based explanations include the societal development of gender roles, ${ }^{24}$ and the parental investment evolutionary theory which suggests females experience a more intense caring attachment to offspring than males. ${ }^{17}$ Any of these hypotheses could potentially be extrapolated into enhanced patient empathic connection by females in the paramedic environment. While this research was cross-sectional in nature, future research could examine these phenomena at a closer level within small-group learning where the majority of paramedic clinical learning is undertaken.

Table 3. MCRS comparative results $(n=783)$

\begin{tabular}{|c|c|c|c|c|}
\hline Scale & Age & Gender & Year level & University \\
\hline $\begin{array}{l}\text { MCRS } \\
\text { Intellectual } \\
\text { Disability }\end{array}$ & $\begin{array}{c}F=1.46 \\
p=0.036\end{array}$ & $\begin{array}{l}t=2.76 \\
p=0.006\end{array}$ & $\begin{array}{c}F=0.38 \\
p=0.764\end{array}$ & $\begin{array}{c}F=1.05 \\
p=0.004\end{array}$ \\
\hline $\begin{array}{l}\text { MCRS } \\
\text { Substance } \\
\text { Abuse }\end{array}$ & $\begin{array}{c}F=0.93 \\
p=0.586\end{array}$ & $\begin{array}{l}t=6.34 \\
p=0.526\end{array}$ & $\begin{array}{l}F=0.59 \\
p=0.617\end{array}$ & $\begin{array}{c}F=3.20 \\
p=0.386\end{array}$ \\
\hline $\begin{array}{l}\text { MCRS } \\
\text { Attempted } \\
\text { Suicide }\end{array}$ & $\begin{array}{l}F=1.21 \\
p=0.178\end{array}$ & $\begin{array}{l}t=9.46 \\
p=0.345\end{array}$ & $\begin{array}{l}F=0.74 \\
p=0.527\end{array}$ & $\begin{array}{c}F=1.92 \\
p=0.075\end{array}$ \\
\hline $\begin{array}{l}\text { MCRS } \\
\text { Acute Mental } \\
\text { Illness }\end{array}$ & $\begin{array}{c}F=1.39 \\
p=0.062\end{array}$ & $\begin{array}{l}t=2.30 \\
p=0.021\end{array}$ & $\begin{array}{c}F=0.44 \\
p=0.723\end{array}$ & $\begin{array}{c}F=2.01 \\
p=0.062\end{array}$ \\
\hline
\end{tabular}

The lowest MCRS mean score was substance abuse $(\mathrm{M}=41.57, \mathrm{SD}=12.29)$. This is a concerning statistic as empathetic interactions by healthcare workers with patients who have substance abuse disorders have been linked to increased likelihood of the patient reaching out for help, as well as improved patient outcomes. ${ }^{25}$ Patients with substance abuse problems have better health outcomes when healthcare staff are accepting and non-judgmental in attitude, and give the impression of viewing patients health concerns seriously. ${ }^{25}$ There is evidence to suggest that negative attitudes in relation to substance abuse can be linked back to a perceived education deficit in a number of undergraduate healthcare courses, both nationally and internationally. ${ }^{26}$ Educational programs that focus on drugs and alcohol have the capacity to improve student attitudes and confidence in interacting with substance users, and so should form an important cornerstone in the design of empathetic undergraduate paramedic curricula.

However it was also seen that CSU and MU differed in MCRS empathy levels relating to intellectual disability, with CSU demonstrating a mean difference of 4.98 points above MU ( $p=0.004)$. These universities may need to examine their course structure in these areas in relation to other Australian paramedic programs, and incorporate specific educational interventions to target these lower empathetic responses by their students. Differences across each of the variables also raise questions around the educational strategies used in each respective curriculum. For example, is the same attention given to these common 'call-outs' compared with other topics that are historical in nature and less contemporary. Moreover, are findings a result of personality, cultural or spiritual beliefs? If so, these might also raise further questions surrounding the standardisation of admissions into paramedic programs in Australia.

In general, empathy levels across each of the medical conditions declined as students progressed through the coursework program. The frequently cited reason for this decline is that, as students progress through their education, they are exposed to more clinical placement education opportunities and professional socialisation resulting in cynicism development, de-humanisation of situations and 'burn-out', ${ }^{2,10,18}$ Whilst there is some exposure to patients and clinical opportunities in first year, paramedic clinical placements begin to occur in earnest during second and third year at MU, ECU, QUT, VU, UT, CSU and LTU. Further longitudinal data is required to ascertain whether these data will alter over time.

Despite the evidence that suggests that higher empathy levels leads to better patient outcomes and care, one paper was identified as having a different hypothesis on paramedic empathy levels. Grevin suggests paramedic students may be predisposed to personality traits that lead to intrinsically lower empathy levels naturally. ${ }^{8}$ This comparatively lower empathy level is also demonstrated in a 2010 study of paramedic, nursing, midwifery, occupational therapy, physiotherapy and health science students, in which paramedic students were shown to have the lowest mean empathy scores. ${ }^{10}$ Grevin suggests that lower paramedic empathy levels may in fact be an adaptive mechanism that allows individuals to function in a constantly stressful and emotional work environment. ${ }^{8}$ This could raise questions as to whether it is better to have higher paramedic empathy levels leading to better patient care and outcomes, or lower empathy levels enabling paramedics to ensure personal protection against emotional involvement.

\section{Limitations}

This study is potentially limited by the use of convenience sampling. This method, while being easier to recruit participants, it may not recruit a representative sample of students. Consequently, those students who did volunteer to participate may themselves bias the results. Caution is required when interpreting the results as the MCRS is a selfreporting questionnaire. Therefore results of the students' reported views and perceptions may differ from their actual empathetic attitudes either in private or when confronted with a patient presenting with one of the clinical situations. The use of qualitative research methods such as focus groups or semi-structured interviews may help with this.

\section{Conclusion}

The findings from this study found that student reported poor empathetic regard for patients with substance abuse, while female students report higher levels of empathy than 
their male colleagues across each medical condition. The overall findings provide a framework for educators to begin constructing guidelines focusing on the need to incorporate, promote and instil empathy into paramedic students in order to better prepare them for future out-of-hospital healthcare practice. Further longitudinal studies are encouraged by other research teams.

\section{Acknowledgements}

We would like to thank the students for participating and completing the questionnaires.

\section{Conflict of Interest}

The authors declare that they have no conflict of interest.

\section{References}

1. Fields SK, Mahan P, Tillman P, Harris J, Maxwell K, Hojat M. Measuring empathy in healthcare profession students using the Jefferson Scale of Physician Empathy: health provider- student version. J Interprof Care. 2011;25(4):287-93.

2. Williams B, Boyle M, Earl T. Cross sectional measurement of empathy levels in undergraduate paramedic students. Prehospital and Disaster Medicine. In press, 2012.

3. Regehr C, Goldberg G, Hughes J. Exposure to human tragedy, empathy, and trauma in ambulance paramedics. Am J Orthopsychiatry. 2002;72(4):505-13

4. Hojat M, Louis DZ, Markham FW, Wender R, Rabinowitz C, Gonnella JS. Physicians' empathy and clinical outcomes for diabetic patients. Acad Med. 2011;86(3):359-64.

5. Wahlin U, Wieslander I, Fridlund B. Loving care in the ambulance service. Intensive Crit Care Nurs. Intensive \& Critical Care Nursing. 1995;11(6):306-13.

6. Nordby $\mathrm{H}$, Nohr O. Communication and empathy in an emergency setting involving persons in crisis. Scand J Trauma Resusc Emerg Med. 2008;16:5.

7. Kliszcz J, Nowicka-Sauer K, Trzeciak B, Nowak P, Sadowska A. Empathy in health care providers - validation study of the Polish version of the Jefferson Scale of Empathy. Adv Med Sci. 2006;51:219-25.

8. Grevin F. Posttraumatic stress disorder, ego defense mechanism and empathy among urban paramedics. Psychol Rep. 1996;79(2):13.

9. Brown T, Boyle M, Williams B, Molloy A, Palermo C, McKenna L, et al.
Predictors of empathy in health science students. J Allied Health. 2011;40(3):143-

10. Boyle M, Williams B, Brown T, Molloy A, McKenna L, Molloy L, et al. Levels of empathy in undergraduate health science students. Int J Med Educ. 2010;1(1). 11. McKenna L, Boyle M, Brown T, Williams B, Molloy A, Lewis B, et al. Levels of empathy in undergraduate midwifery students: an Australian cross-sectional study. Women Birth. 2011;24(2):80-4.

12. Nunes P, Williams S, Sa B, Stevenson K. A study of empathy decline in students from five health disciplines during their first year of training. Int J Med Educ. 2011;2:12-7.

13. Brown T, Williams B, Boyle M, Molloy A, McKenna L, Molloy L, et al. Levels of empathy in undergraduate occupational therapy students. Occup Ther Int. 2010;17(3):135-41

14. Libbam R, McMillan, Shannon D. Program evaluation of nursing school instruction in measuring students' perceived competence to empathetically communicate with patients. Nurs Educ Perspect. 2011;32(3):5.

15. Modic MB, Schoessler M. Preceptorship: empathy. J Nurses Staff Dev. 2011;27(4):2.

16. Hojat M, Mangione S, Nasca TJ, Rattner S, Erdmann JB, Gonnella JS, et al. An empirical study of decline in empathy in medical school. Med Educ. 2004;38(9):934-41.

17. Magalhaes E, Salgueira AP, Costa P, Costa MJ. Empathy in senior year and first year medical students: a cross-sectional study. BMC Med Educ. 2011;11:52.

18. Chen D, Lew R, Hershman W, Orlander J. A cross-sectional measurement of medical student empathy. J Gen Intern Med. 2007;22(10):1434-8.

19. Neumann M, Edelhauser F, Tauschel D, Fischer MR, Wirtz M, Woopen C, et al. Empathy decline and its reasons: a systematic review of studies with medical students and residents. Acad Med. 2011;86(8):996-1009.

20. Christison G, Haviland M, Riggs $M$. The medical condition regard scale: measuring reactions to diagnosis. Acad Med. 2002;77(3):257-62.

21. Hair J, Anderson R, Tatham R, Black W. Multivariate data analysis with readings: New Jersey, Prentice Hall; 1995.

22. Baron-Cohen S. The essential difference: male and female brains and the truth about autism. Portland: Basic Books; 2004

23. Looi JC. Empathy and competence. Med J Aust. 2008;188(7):414-6.

24. Mestre MV, Samper P, Frias MD, Tur AM. Are women more empathetic than men? A longitudinal study in adolescence. Span J Psychol. 2009;12(1):76-83.

25. Godlaski TM, Butler L, Heron M, Debord S, Cauvin L. A qualitative exploration of engagement among rural women entering substance user treatment. Subst Use Misuse. 2009;44(1):62-83.

26. Kelleher S, Cotter P. A descriptive study on emergency department doctors' and nurses' knowledge and attitudes concerning substance use and substance users. Int Emerg Nurs. 2009;17(1):3-14. 